\title{
KUALITAS PELAYANAN PROGRAM JAMPERSAL MELALUI SISTEM KLAIM (REIMBURSEMENT) DALAM MENINGKATKAN KEPUASAN MASYARAKAT (Studi Dinas Kesehatan Kabupaten Sumenep)
}

\author{
Oleh : \\ Sari Munaili ${ }^{1}$, Ida Syafriyani ${ }^{2}$, Ir. Alqaf Harto ${ }^{3}$ \\ Fakultas Ilmu Sosial dan Ilmu Politik, Program Studi Administrasi Publik, Universitas \\ Wiraraja Madura \\ E-mail: sarimunaili9@gmail.com
}

\begin{abstract}
Abstrak
Kualitas pelayanan publik merupakan salah satu hal yang sangat penting demi kemajuan negara. Karena melalui suatu pelayanan kebutuhan dan keinginan masyarakat dapat terpenuhi dengan sepenuhnya. Salah satunya adalah Pelayanan kesehatan yang dimana kesehatan merupakan hal terpenting untuk menentukan kualitas sumber daya manusia dalam meningkatkan kelangsungan hidup apabila disuatu negara masyarakatnya dalam segi kesehatan sudah terpenuhi maka generasi yang akan meneruskan akan menjadi generasi yang sehat dan cerdas. Dinas kesehatan kabupaten sumenep telah melakukan salah satu program jampersal melalui sistem klaim untuk mengurangi kematian ibu dan bayi yang dimaksudkan untuk meningkatkan pelayanan publik dan kepuasaan masyarakat.

Metode penelitian yang digunakan adalah metode kualitatif. Teknik pengumpulan data dalam penelitian ini menggunakan wawancara, observasi, dan dokumentasi. Analisis data dalam penelitian ini menggunakan beberapa tahap yaitu reduksi data, penyajian data, dan kesimpulan. Hasil penelitian dari Kualitas Pelayanan Program Jampersal Melalui Sistem Klaim (Reimbursement) dalam Meningkatkan Kepuasan Masyarakat menunjukkan bahwa : Pertama, Standar Pelayanan pelanggan berupa standar kualitas sudah baik dibuktikan dengan terlaksananya program jampersal sesuai dengan standar yang telah ada. Kedua, Customer Redress, di dinas kesehatan kabupaten sumenep sudah cukup baik karena selama pelaksanaan program jampersal biaya benar-benar digratiskan. Ketiga, Quality Guaranties komitmen organisasi di dinas kesehatan kabupaten sumenep sudah cukup baik karena adanya inovasiinovasi terbaru setiap tahunnya. Keempat, Quality Inspector, Baik dinas kesehatan maupun rumah sakit, bidan desa dan puskesmas sudah melakukan kerjasama yang baik, Tetapi masih kurang maksimal karena masih banyak masyarakat yang masih belum mengetahui program jampersal. Kelima, Customer Komplain System, Pemberian respon atas keluhan-keluhan masyarakat juga sudah baik namun masih perlu ada peningkatan kembali. Keenam, Ombudsmen, selama ini yang diberikan oleh pihak rumah sakit maupun dinas kesehatan juga sudah cukup baik.
\end{abstract}

Kata Kunci: Kualitas Pelayanan Publik, Kepuasaan Masyarakat 


\section{PENDAHULUAN}

Perkembangan zaman dari waktu ke waktu diharapkan mampu melakukan perubahan yang semakin membaik. Terutama dalam bidang pelayanan yang diberikan oleh pemerintah kepada masyarakat yaitu seperti pelayanan kesehatan, pelayanan pendidikan dan pelayanan perbankan. Sehingga dalam hal ini perlu adanya peningkatan kualitas pelayanan yang diberikan oleh pemerintah untuk menunjang kehidupan berbangsa dan bernegara. Maka dengan ini perlu adanya kerjasama yang baik antara pemerintah dengan masyarakat untuk meningkatkan pelayanan publik yang diberikan sehingga dapat terwujud kesejahteraan masyarakat.

Salah satu program yang dilakukan di kabupaten sumenep adalah program Jampersal (Jaminan Persalinan) program ini dibuat karena banyaknya angka Kematian ibu dan Anak. Jaminan persalinan menjadi salah satu bentuk program pemerintah melalui bentuk pelayanan kesehatan yang diharapkan mampu untuk meningkatkan kesejahteraan masyarakat, dengan pelayanan publik yang baik maka masyarakat dapat merasakan kepuasan tersendiri terhadap pelayanan yang diberikan pemerintah. Dalam rangka untuk memenuhi kebutuhan dan harapan masyarakat sehingga masyarakat memperoleh kepuasan maka pemerintah harus mampu meningkatkan kualitas pelayanan yang diberikan sesuai dengan standar opersional prosedur yang berlaku sehingga akan bebas dari kekurangan dan kerusakan demi tercapainya kepuasan masyarakat.

Jaminan Persalinan merupakan jaminan yang ditanggung oleh negara yang bentuknya melalui pelayanan. Dalam penggantian biaya layanan jampersal pemerintah menetapkan sistem klaim (Reimbursement) yaitu proses Klaim dilakukan oleh klinik,rumah sakit swasta dan polindes berdasarkan pelayanan yang telah diberikan kepada ibu hamil. Pengajuan sistem klaim diajukan ke Tim pengelolaan dinas kesehatan kabupaten/kota dengan dilengkapi bukti penunjang pelayanan. Kemudian tim pengelola dinkes kabupaten/kota melakukan verifikasi, pemberian persetujuan dan akhirnya membayar tagihan klaim.

Angka kematian ibu dan angka kematian balita di kabupaten sumenep yaitu angka kematian ibu tahun 2016 tecatat sebanyak 11 orang dan di tahun 2017 sebanyak 8 orang, sedangkan angka kematian balita pada tahun 2016 sebanyak 36 kasus dan di tahun 2017 sebanyak 27 kasus. Sesuai dengan rencana pembangunan jangka menengah daerah kabupaten sumenep tahun 2016-2021, sektor kesehatan ditekankan pada 3 arah 
kebijakan diantaranya, meningkatkan kualitas kesehatan masyarakat guna mencapai angka harapan hidup ( $\mathrm{AHH}$ ) masyarakat 71,50 di tahun 2021.

Dari sekian banyak masalah tentang angka kematian bayi, balita dan ibu melahirkan pada tahun 2016 maka Dinas Kesehatan Kabaputen Sumenep menerapkan program Jaminan Persalinan. Program Jampersal dalam rangka peningkatan kesehatan masyarakat, sasaran program jampersal adalah kepada ibu hamil, bersalin, dan nifas dari keluarga miskin dan kurang mampu dikabupaten sumenep yang tidak memiliki jaminan kesehatan seperti jaminan kesehatan dari BPJS maupun kartu indonesia sehat (KIS). Jampersal dikabupaten sumenep sudah diterapkan dari tahun 2017. Sehingga pada tahun 2018 ini diharapkan adanya kemajuan dalam program ini dengan melakukan secara rutin sosialisasi kepada masyarakat. Hal ini diharapkan agar masyarakat dikabupaten sumenep tingkat angka kematian ibu dan bayi yang meninggal saat persalinan karena adanya masalah pembiayaan dapat diminimalisir menjadi tidak ada lagi.

Berdasarkan penjelasan diatas maka dapat disimpulkan bahwa disini peneliti ingin meneliti "Kualitas Pelayanan

Program Jampersal Melalui Sistem Klaim (Reimbursement) dalam
Meningkatkan Kepuasaan Masyarakat di Kabupaten Sumenep".

\section{TINJAUAN TEORITIS}

\section{PELAYANAN PUBLIK}

Pelayanan Publik menurut Sinambela (2006:5) adalah sebagai kegiatan yang dilakukan oleh pemerintah terhadap sejumlah manusia yang memiliki setiap kegiatab yang menguntungkan dalam suatu kumpulan atau kesatuan, dan menawarkan kepuasan meskipun hasilnya tidak terikat pada suatu produk secara fisik. ( Dyah, Arif, 2014 : 115).

Menurut Menteri Pemberdayaan Aparatur Negara (1993), mengemukakan bahwa pelayanan adalah segala bentuk kegiatan pelayanan dalam bentuk barang atau jasa dalam rangka upaya pemenuhan kebutuhan masyarakat. (Harbani Pasolong, 2016 : 128).

\section{KUALITAS PELAYANAN PUBLIK}

Menurut Kasmir Tahun (2005:31), mengatakan bahwa pelayanan yang baik adalah kemampuan seseorang dalam memuberikan pelayanan yang dapat memberikan kepuasan kepada pelanggan dengan standar yang telah ditentukan. (Harbani Pasolong, 2016 : 133).

Selain itu, menurut Morgan dan Murgantroyd (1984) kualitas merupakan bentuk-bentuk istimewa dari auatu produksi atau pelayanan yang mempunyai kemampuan untuk memuaskan kebutuhan 
masyarakat. Sedangkan menurut Logothetis (1992) menyatakan bahwa kualitas adalah kebutuhan dan harapan pelanggan atau klien serta kemudian memperbaikinya secara berkesinambungan.

Jadi Kualitas pelayanan publik dapat diartikan sebagai kemampuan pemerintah untuk memenuhi harapan dan kebutuhan masyarakat yang berupa barang atau jasa yang bebas dari kekurangan dan kerusakan demi terciptanya kepuasan masyarakat. ( Dyah, Arif. 2014 : 51-52)

\section{KEPUASAN MASYARAKAT}

Menurut Kotler dalam Tjiptono menandaskan bahwa kepuasan pelanggan adalah tingkat perasaan seseorang (pelanggan) setelah membandingkan dengan kinerja yang ia rasakan, dibandingkan dengan harapannya. (Harbani Pasolong, 2016 : 145).

Kepuasan masyarakat yang dapat diberikan oleh pemerintah maka akan terciptanya kepuasan pelanggan yang dapat memberikan beberapa manfaat yaitu hubungan antara pelanggan dengan instansi menjafi harmonis, memberikan dasar yang baik bagi pembeli (pemakaian) ulang serta terciptanya loyalitas dari pelanggan dalam bentuk rekomendasi dari mulut ke mulut yang semuanya menguntungkan semua pihak.
JAMINAN PERSALINAN

\section{( JAMPERSAL )}

Jaminan Persalinan merupakan jaminan pembiayaan yang digunakan untuk pemeriksaan kehamilan, pertolongan persalinan, pelayanan nifas termasuk pelayanan $\mathrm{KB}$ pasca persalinan dan pelayanan bayi baru lahir yang pembiayaannya dijamin oleh pemerintah. Jaminan persalinan merupakan salah satu terobosan yang ditempuh pemerintah dalam usaha menurunkan AKI (Angka Kematian Ibu). Terobosan ini penting mengingat masih banyaknya ibu hamil yang belum memiliki jaminan pembiayaan untuk persalinannya. Program Jaminan Persalinan diterapkan di kabupaten sumenep pada tahun 2017 sampai dengan tahun ini, Program jampersal sampai tahun ini mengalami meningkatan dari pasien pengguna program jampersal yang semakin meningkat setiap tahunnya.

\section{SISTEM KLAIM (REIMBURSEMENT)}

Sistem klaim (Reimbursement) yaitu proses Klaim dilakukan oleh klinik,rumah sakit swasta dan polindes berdasarkan pelayanan yang telah diberikan kepada ibu hamil. Pengajuan sistem klaim diajukan ke Tim pengelolaan dinas kesehatan kabupaten/kota dengan dilengkapi bukti penunjang pelayanan. Kemudian tim pengelola dinkes kabupaten/kota melakukan verifikasi, pemberian 
persetujuan dan akhirnya membayar tagihan klaim.

\section{METODE PENELITIAN}

Adapun metode penelitian yang digunakan adalah metode penelitian Kualitatif. Metode Penelitian Kualitatif didefinisikan sebagai metode penelitian yang berlandaskan pada filsafat postpositivme, digunakan untuk meneliti pada kondisi objek yang alamiah ( sebagai lawannya adalah Eksperimen) dimana peneliti adalah sebagai instrumen kunci, teknik pengumpulan data dilakukan dengan triangulasi (gabungan), analisis data bersifat induktif/kualitatif, dan hasil penelitian kualitatif lebih menekankan makna dari pada generalisasi. (Sugiyono, $2018: 9)$.

Penelitian ini dilakukan pada Dinas Kesehatan Kabupaten Sumenep, sedangkan yang menjadi objek penelitian ini adalah Masyarakat atau Ibu hamil penggunaan Program Jampersal di Kabupaten Sumenep.

Teknik Pengumpulan data yang digunakan dalam penelitian ini adalah Wawancara, Observasi, dan Dokumentasi. Sedangkan Teknik Analisis datanya menggunakan Data reduction, Data display, dan Conclusion drawing/verification.

\section{HASIL DAN PEMBAHASAN}

Hasil penelitian terkait dengan beberapa indikator yang menjadi tolak ukur tentang Bagaimana Kualitas Pelayanan Program Jampersal Melalui Sistem Klaim (Reimbursement) dalam Meningkatkan Kepuasan Masyarakat, yang dalam penelitian ini untuk mengetahui bagaimana kualitas pelayanan program jampersal melalui sistem Klaim (Reimbursement) dalam meningkatkan kepuasan masyarakat khususnya di kabupaten Sumenep dalam bidang kesehatan difokuskan pada penelitian yang diambil menurut Clinton dalam Warella (2004) (Harbani Pasolong, 2016 : 140) yang meliputi; 1) Standar Pelayanan Pelanggan berupa standar kualitas. 2) Customer Redress. 3).Quality Guaranties. 4) Quality Inspector 5). Customer Komplain System. 6). Ombudsmen yang Dalam hal ini peneliti telah melakukan penelitian kepada informan kunci, informan utama maupun informan pendukung untuk menggali berbagai informasi yang dibutuhkan. Yaitu

\subsubsection{Standar Pelayanan Pelanggan} berupa standar kualitas

Berbicara masalah Jampersal ini, Pemerintah mengalokasikan Dana Khusus atau DAK di Kabupaten Sumenep pada Tahun 2020 sebesar \pm 2,5 milliar dengan jumlah pasien pada tahun 2020 di 
bulan Mei telah tercatat sebanyak 125 pasien dengan kriteria ibu hamil yang memiliki resiko tinggi saat melahirkan. Program kegiatan akan efisien apabila birokrasi pelayanan dapat menyediakan input pelayanan, seperti biaya dan waktu pelayanan yang meringankan masyarakat pengguna jasa. Demikian pula pada sisi output pelayanan, birokrasi secara ideal harus dapat memberikan produk pelayanan yang berkualitas, terutama dari aspek biaya dan waktu pelayanan. Di dinas Kesehatan Kabupaten sumenep dari segi standar pelayanan yang telah diberikan kepada para pasien pengguna program jampersal selama ini telah sesuai dengan standar pelayanan yang telah di tetapkan. Salah satunya yaitu standar pelayanan prosedur dari mulai awal menggunakan program jampersal sampai dengan selesai menggunakan program jampersal atau pasien telah melahirkan.

\subsubsection{Customer Redress}

Sebagai bagian dari upaya untuk memberikan pelayanan yang terbaik bagi masyarakat dalam program Jampersal ini Dinas Kesehatan terus mengembangkan pelayanan yang lebih baik, Dinas Kesehatan terus mengidentifikasi dan memperbaiki pelayanan, salah satunya Customer Redress Skema ganti rugi pelanggan juga telah dikembangkan terhadap sejumlah langkah layanan berdasarkan keluhan atau ketidakpuasan masyarakat terkait pelaksanaan sistem pelayanan yang diberikan. dimana yang dalam hal ini RSUD. Moh. Anwar Kabupaten Sumenep sebagai satu-satunya tempat pelaksana program Jampersal yang telah dari awal melakukan kerja sama dengan Dinas Kesehatan itu sendiri, harus benar-benar memberikan pelayanan yang terbaik dan apabila dikemudian hari ada keluhan dari beberapa pasien tentang ketidaksesuaian pelayanan atau pihak Rumah Sakit

\subsubsection{Quality Guaranties}

Program Jampersal di Kabupaten Sumenep ini telah menawarkan kualitas dan kuantitas pelayanan yang terbaik dimana setiap pelayanan yang digunakan telah dipertimbangkan dengan matang sehingga akan benar-benar memberikan pelayanan yang terbaik untuk masyarakat. Sehingga dengan pelayanan yang ada ini akan memberikan solusi dan kepuasan tersendiri kepada pasien, khususnya para Ibu dan bayinya yang melakukan persalinan, dengan harapan agar pasien tidak merasa dirugikan oleh program ini.

\subsubsection{Quality Inspector}

Quality Inspector yang dalam penelitian ini dimaksudkan pada suatu tim yang terdiri dari para profesional maupun tokoh masyarakat yang memberikan pelayanan publik dalam hal ini difungsikan untuk memberikan sosialisasi berkenaan 
dengan Jampersal. Opsi kebijakan yang dikemukakan terkait kegiatan sosialisasi Jampersal yaitu lini pemerintah baik ditingkat Kecamatan, tingkat Desa dan Puskesmas yang sebagai pelayanan publik disini difungsikan untuk membantu Dinas Kesehatan untuk menyampaikan program Jampersal ini kepada masyarakat, dan ikut berpartisipasi dan bekerja sama dalam memberikan pemahaman kepada masyarakat agar mereka mengetahui dengan jelas bagaimana proses dan prosedur dalam Program Jampersal. dan tanpa kerja sama yang baik antara Dinas Kesehatan, Puskesmas, Kecamatan dan Kepala Desa maka mustahil untuk sampai kepada masyarakat dengan baik bahkan akan sangat sulit untuk memberikan pemahamantentang program Jampersal ini di kalangan masyarakat.

\subsubsection{Customer Komplain System}

Customer Komplain System adalah penampungan keluhan yang dihadapi dari pelanggan dan agar segera memberikan solusi yang terbaik akan keluhan tersebut. Yang mana dalam hal ini sistem keluhan pelanggan yang efektif dimaksudkan untuk dapat meningkatkan reputasi manajemen organisasi yang berfokus pada pelanggan dan kepercayaan mereka.

Adapun beberapa solusi yang diberikan dari segi pelaksanaan pelayanan Jampersal di Kabupaten Sumenep yaitu keluhan masyarakat telah menjadi inspirasi dan motivasi besar Pihak Dinas Kesehatan, dimana pasien yang jauh jangkauannya akan sangat merasa banyak memakan waktu dan tenaga untuk mengikuti program Jampersal ini, oleh hal tersebut Dinas Kesehatan Kabupaten Sumenep menyedikan Rumah Tunggu Kelahiran (RTK) yang dimaksudkan untuk menyediakan tempat bagi Pasien yang dari kepulauan-kepulauan atau yang jauh jangkauannya dari Rumah Sakit. Karena Program Jampersal di Kabupaten Sumenep hanya bekerjasama dengan RSUD. Moh. Anwar maka otomatis harus melakukan persalinan di RSUD Moh. Anwar (RTK) Rumah Tunggu Kelahiran ini juga dijadikan penampungan keluhan dan pertanyaan-pertanyaan tentang masalah Ibu hamil, proses kelahiran, serta kesehatan bayi dan anak, dengan demikian kami akan mampu memberikan pelayanan terbaik bagi mereka.

\subsubsection{Ombudsmen}

Dalam hal ini Dinas Kesehatan di Kabupaten Sumenep sebagai lembaga pengawasan program Jampersal. Berdasarkan dari data lapangan yang telah dikumpulkan oleh peneliti melalui hasil wawancara terkait lembaga Ombudsman yang dalam hal ini adalah Dinas Kesehatan Kabupaten Sumenep telah menjalankan tugas dan fungsinya dengan baik dimana yang dalam hal ini Dinas Kesehatan telah 
mengadakan kesepakatana bersama dengan RSUD Moh. Anwar untuk memberikan pelayanan yang terbaik kepada masyarakat penggunan Jampersal, dan apabila dikemudian hari ada keluhan dari beberapa pasien tentang ketidaksesuaian pelayanan atau pihak Rumah Sakit Dalam hal ini secara nyata terbukti melakukan hal-hal berikut

\section{PENUTUP}

Berdasarkan pemaparan hasil penelitian maupun pembahasan diatas, maka dapat disimpulkan dengan secara singkat bahwa :

1. Standar Pelayanan Pelanggan berupa Standar Kualitas disini dinas kesehatan telah sesuai dengan standar yang telah ada di dinas lesehatan kabupaten sumenep. hal ini dapat dilihat pada pelaksanaan program jampersal yang tetep berjalan sampai tahun ini serta adanya inovasi-inovasi yang selalu ada disetiap tahunnya berupa sarana dan prasarana yang terus ditingkatkan.

2. Customer Redress yaitu dinas kesehatan kabupaten sumenp ini dalam pelaksanaan Customer Redress atau Skema ganti rugi tidak pernah memberikan kompensasi kepada pasien pengguna program jampersal karena selama pelaksaan program jampersal masih tidak ada keluhan dalam sistem pembiayaannya hanya saja ada keluhan diawal pelaksanaan mengenai sistem program jampersal yang terlalu sulit tetapi dapat terselesaikan dengan adanya sosialisasi dan pemberitahuan yang lebih kepada masyarakat.

3. Quality Guaranties yaitu Dinas Kesehatan Kabupaten Sumenep dalam komitmen organisasi yang tinggi sehingga selalu ada inovasiinovasi terbaik yang diberikan setiap tahunnya dengan mengidentifikasi dari beberapa masukan dari para pengguna program jampersal yang dimana akan disosialisasikan kepada camat, kepala desa maupun bidan desa setempat.

4. Quality Inspector yaitu dalam hal ini dinas kesehatan kabupaten sumenep dalam meningkatkan pelayan program jampersal bekerjasama dengan beberapa tim kesehatan baik dalam tingkat Kecamatan, tingkat Desa dan Puskesmas yang dalam hal ini berbentuk sosialisasi yang dilakukan setiap tahunnya.agar masyarakat dapat mengetahui dengan jelas bagaimana proses dan prosedur dalam program jampersal di kabupaten sumenep

5. Customer Komplain System yaitu Dinas Kesehatan Kabupaten 
Sumenep dalam menyelesaikan masalah atau keluhan masyarakat yaitu salah satu inovasi yang dilakukan adalah menyediakan Rumah Tunggu Kelahiran (RTK) kepada pasien yang memiliki jangkaun jauh seperti dikepulauan. RTK ini diperuntukkan kepada pasien yang hampir mendekati persalinan serta sebagai salah satu tempat untuk menampung setiap masalah ataupun pertanyaan mengenai masalah ibu hamil, proses kelahiran dan lain sebagainya.

6. Ombudsmen yaitu membantu pelanggan dalam memecahkan masalah apabila mereka merasa tidak puas dengan pelayanan yang diberikan. Dimana Dinas Kesehatan Kabupaten Sumenep telah menjalankan tugas dan fungsinya dengan baik dimana dalam hal ini Dinas Kesehatan telah mengadakan kesepakatan bersama dengan RSUD Moh. Anwar untuk memberikan pelayanan yang terbaik kepada masyarakat penggunan Jampersal, dan apabila dikemudian hari ada keluhan dari beberapa pasien tentang ketidaksesuaian pelayanan atau pihak rumah sakit. Dalam hal ini secara nyata maka pihak rumah sakit dan Dinas Kesehatan Kabupaten Sumenep sepenuhnya akan bertanggung jawab dan akan mencari penyelesaian terhadap permasalahan yang telah dihadapi dengan melakukan evaluasi dan mencari solusi terbaik.

Berdasarkan hasil penelitian yang telah dilakukan, maka saran yang dapat disampaikan adalah :

1. Diharapkan Dinas Kesehatan Kabupaten Sumenep dapat meningkatkan kualitas pelayanan program jampersal dikabupaten sumenep untuk meningkatkan kepuasaan masyarakat terhadap pelayanan yang diberikan pemerintah.

2. Diharapkan Dinas Kesehatan Kabupaten Sumenep dalam menyampaikan sosialisasi terkait dengan progran jampersal lebih di perjelas baik tentang prosedur maupun proses yang akan digunakan untuk mengikuti program jampersal.

3. Diharapkan Dinas Kesehatan Kabupaten Sumenep lebih meningkatkan sarana dan prasarana untuk menunjang pelaksanaan program jamperaal di kabupaten Sumenep.

4. Diharapkan Dinas Kesehatan Kabupaten Sumenep dapat lebih meningkatkan pelayanan kesehatan 
yang lebih baik khususnya program jampersal agar terua terlaksana di kabupaten sumenep untuk membantu masyarakat yang kurang mampu dalam melakukan persalinan.

\section{DAFTAR PUSTAKA}

\section{BUKU}

Bagong, Sutinah. 2011. Metode Penelitian Sosial : Berbagai Alternatif Pendekatan. Jakarta: Kencana.

Creswell. 2013. Research Design Kualitatif,Kuantitatif, dan Mixed. Yogyakarta: Pustaka Pelajar.

Dyah, Arif. 2014. Manajemen Birokrasi dan

Kebijakan. Yogyakarta: Pustaka Pelajar.

Etta, Sopiah. 2010. Metodelogi Penelitian-

Pendekatan Praktis dalam

Penelitian. Yogyakarta: CV Andi Offset.

Harbani, Pasolong. 2016. Teori Administrasi Publik. Bandung: Alfabeta.

Jamaluddin. 2015. Metode Penelitian Administrasi Publik Teori dan Aplikasi. Yogyakarta: Gava Media.

Sugiyono. 2017. Metode Penelitian :

Kuantitatif, Kualitatif, dan $R \& D$.

Bandung: Alfabeta.
Taufiqurokhman. 2014. Kebijakan Publik: Pendelegasian Tanggung Jawab negara kepada Presiden selaku Penyelenggara Pemerintahan. Jakarta: Fisip Universitas moestopo pers.

\section{ONLINE}

Ahmad, dkk. 2013. Pelaksanaan Program Jaminan Persalinan (Jampersal) di Dinas Kesehatan Kabupaten Buol. Dalam Jurnal AKK. Vol.2 No. 2, Mei. Online.

http://download.portalgaruda.org/ar ticle.php $?=94545 \& v a l=2172$.

Diunduh tanggal 20 Desember 2019. Maslekhah, dkk. 2013. Evaluasi Program Jampersal di Kabupaten Pekalongan Tahun 2011. Dalam jurnal Pemerintahan. Vol. No. Maret. Online.

http://download.portalgaruda.org/ar ticle.php? article $=74874 \& \mathrm{val}=4924$.

Diunduh tanggal 19 Desember 2019. Anggrini, dkk. Evaluasi Program Jampersal (Jaminan Persalinan) di Puskesmas Ngesrep Kota Semarang. Online. https://media.neliti.com/media/publ ications/178270. pdf. Diunduh tanggal 20 Desember 2019.

Isna, N.P. 2008 .Implementasi Program Jaminan Persalinan (jampersal) di Puskesmas Ngrayun (Studi deskriptif tentang faktor-faktor yang 
mempengaruhi implementasi

program jampersal di puskesmas ngayun kabupaten ponogoro). Jurnal Kebijakan dan Manajemen Publik. Online. Diunduh tanggal 20 Desember 2019.

Darmawan, dkk. 2017. Evaluasi Program Jaminan Persalinan (Jampersal) di Puskesmas Pelitakan Kabupaten Polewali Mandar. Dalam jurnal Administrasi Publik. Vol. 3 No. 2 Agustus. Online.

https:///journal.unismuh.ac.id/index .php/kolaborasi. Diunduh pada tanggal 19 Desember 2019.

\section{SUMBER LAIN}

Fatoni, dkk. 2017. Profil Kesehatan Tahun 2016 Kabupaten Sumenep. Online. www.depkes.go.id. Diunduh tanggal 12 Oktober 2018.

"Demi Mengurangi Angka Kematian Ibu dan Balita, Dinkes Sumenep Sosialisasi Jampersal", News Indonesia, 13 Maret 2018. 